\title{
Simulation Analysis on Mass Concrete Temperature Field of Navigation Lock in Changsha Integrated Hub
}

\author{
Jin Ke, Peng Hui* \\ College of hydraulic \& environmental engineering \\ CTGU \\ Yichang, Hubei, China \\ hpeng1976@163.com
}

\begin{abstract}
Based on the development of Changsha Integrated Hub navigation lock structure engineering, on the finite element program ANSYS platform, using Parametric Design language(APDL) commands to simulate the temperature field analysis during layered pouring of concrete for the upper lock head structure, we carry out the simulation analysis on the temperature field cloud picture and the variation of temperature field with time of each section and important parts of the structure. It has great significance for material selection, construction method and temperature control measures when pouring concrete. And it also has important reference value on the installation of safety monitoring instruments in navigation lock.
\end{abstract}

Key words-mass concrete; upper lock structure; APDL; pouring temperature field; heat of hydration

\section{INTRODUCTION}

In hydraulic concrete structures, a great deal ofhydration heat is generated in the concrete pouring process, as well as the ambient temperature changes have a great influence on the mechanical properties of concrete. Data show the majority of large volume concrete structures in the construction period have appeared cracks and the temperature control problem of the construction period have gradually attracted the attention of the engineering and academic circles. The 1988 report of International Commission on Large Dams(ICOLD) for dam work status displayed: The vast majority of concrete dams which had been built in the world, more or less, have temperature cracks, there were 30 of the 243 suffered catastrophic damage concrete dams were caused by the temperature problem [1].In the process of concretingmass concrete, the concrete structure cracks caused by temperature greatly reduce the durability of the building, which seriously affects the safety and service life of the structure. Also in the lock engineering construction process, the cracks caused by improper temperature control measures are also common.

In this paper, based on actual engineering, the temperature field simulation analysis in the construction process of upper lock head structures are carried out by using finite element

This research was supported by NSFC (National Natural Science Foundation of China) (Granted No.: 51379108).

\author{
Wen Chen, Wu Fan, Yin Shaofei \\ College of hydraulic \& environmental engineering \\ CTGU \\ Yichang, Hubei, China \\ jakeking5@163.com
}

software ANSYS. Through which we can not only examine the rationality of the design results of material selection, structural jointing, construction scheme, and temperature control, but also can reflect the feedback of design, as wellas receive an important reference value on the installation of safety monitoring instruments in navigation lock.

\section{ENGINEERING SITUATION}

Changsha integrated hub project is located downstream of Changsha, the capital city of Hunan Province. It is only $20 \mathrm{~km}$ to $30 \mathrm{~km}$ from the city centre to the dam siteand the traffic is convenient. The hub includes lock, sluice, power plant, dam crest road bridge, fishway, revetment, etc. The ship lock is one of the main buildings of Changsha integrated hub. Lock is arranged at the left bank of the Xiangjiang River, it's a double lock whose level is 2000 tons. The effective size of the chamber is $280 \mathrm{~m} * 34 \mathrm{~m} * 4.5 \mathrm{~m}$ (length * width * water depth on sill) and the design of annual traffic are 98 million tons. And there reserved third line lock position and here the third line lock position was reserved and will be built when the double line ship lock does not meet the navigation capacity in order to meet the needs of economic development.

The upper lock head structure of Changsha integrated hub uses a whole dock structure [2]. It uses a pouring method of "Separate pouring the bottom of the pier, setting up wide construction joints, late pouring joints"in order to reduce the internal force of the bottom. The whole dock structure uses the method of setting two $1.5 \mathrm{~m}$ wide seam in the floor to divide the original width of $62 \mathrm{~m}$ floor into three sections: thelength ofthe middle section is $20 \mathrm{~m}$ and the otherboth sides of the segment is $19.5 \mathrm{~m}$. The upper lock head structure is selected in this simulation analysisand the quantity of concrete is about 58 million $\mathrm{m}^{3}$ using C25 concrete and pouring by 12 layers.The mix proportion of concrete are shown in Table 1.

\section{ACHIEVE UnsteAdy TeMPERATURE FIELD}

\section{A. Calculation Scheme}

Mass concrete casting is usually time-sharing block casting. In the process of the simulation of the upper lock head structure, the construction method is carried out by the 
TABLE I. MIX PROPORTION OF CONCRETE

\begin{tabular}{|c|c|c|c|c|c|c|c|c|}
\hline \multirow{2}{*}{\multicolumn{2}{|c|}{$\begin{array}{c}\text { Mix } \\
\text { Proportion }\end{array}$}} & \multicolumn{7}{|c|}{ (cement+fly ash+slag powder):sand:ston } \\
\hline & & \multicolumn{7}{|c|}{$(0.4+0.4+0.2): 2.77: 7.13: 0.01$} \\
\hline \multicolumn{9}{|c|}{ Concrete materials per cubic meter(kg) } \\
\hline \multirow{2}{*}{ cement } & \multirow{2}{*}{ sand } & \multicolumn{3}{|c|}{ stone } & \multirow{2}{*}{ water } & admixture & \multicolumn{2}{|c|}{ additive } \\
\hline & & $5-25$ & $20-40$ & $40-80$ & & $R-P C$ & $\begin{array}{l}\text { fly } \\
\text { ash }\end{array}$ & slag \\
\hline 215 & 596 & 537 & 307 & 689 & 86 & 2.15 & 86 & 43 \\
\hline
\end{tabular}

method of the floor reserved for wide seam. First of all pouring bottom plate with reserving two $1.5 \mathrm{~m}$ seam and pouring by $2 \mathrm{~m}$ a layer; Secondly, pouring the side pier of the two line navigation lock to the height of $29.7 \mathrm{~m}$ by the use of $3 \mathrm{~m}$ a layer of pouring after the completion of the construction of the water corridor. Finally, pouring concrete of floor wide slit in order to make the floor as a whole. Specific layered construction situation isshown in figure 1 .

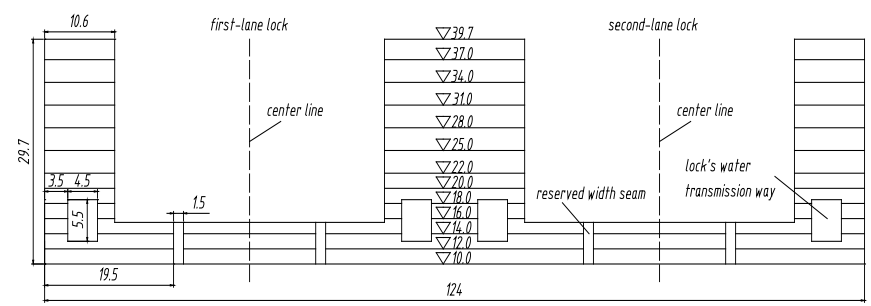

Fig. 1. Layered construction section of the upper lock structure.

According to the structural characteristics and work experience of the upper lock head structure, the temperature cracks easily appear in the bottom of the gate wall, the middle and upper part of the side pier and the water delivery corridor. Therefore, the main observation are the temperature time variation of these three cross-section in the thickness direction in the simulation. In addition, attention should be paid to whole floor temperature field of the reserve wide slit seam.

\section{B. Model Building}

The model is relatively simple on account of that the upper lock head structure is a symmetrical structure. Sluice bottom thick $5.5 \mathrm{~m}$ and the water galleries size: $4.5 \mathrm{~m} * 5.5 \mathrm{~m}$ $(\mathrm{L} * \mathrm{H})$ with $3 \mathrm{~m}$ height from the bottom of the corridor to the ground surface. In the process of simulation analysis, we need not only consider the temperature transfer between the sluice bottom and foundation rock, but also consider the thermal convection flow between the lock conduit culvert with external environment and the external boundary of the upper lock head with external environment. The height of both sides of the pier are $29.7 \mathrm{~m}$, the right side of the first-lane lock is the release sluice and the left side of the second-lane lock reserves the position of the third-lane lock. Therefore, the only consideration is the thermal convection flow between the lock with external environment in the simulation analysis. The entire calculation process needs to use class 2, class 3 and class 4 boundary conditions [3]. The structure model is relatively complex and it's difficult to be analyzed by using ANSYS graphical user operation. So we need to use the powerful programming capabilities APDL to achieve this process.

According to the structural characteristics, the geological and the topographical conditions of the upper lock head structure, we select the following ranges as the finite element calculation area: Selecting the entire upper lock head body as main body of temperature field simulation analysis; Replacing $0 \sim 5 \mathrm{~m}$ deep bedrock with C15 concrete, $5 \mathrm{~m} \sim 30 \mathrm{~m}$ being the original geological layer. Taken along the vertical axis of the gate to extend $30 \mathrm{~m}$ as a lateral boundary at the vertical axis of the bedrock and selected the actual structure as the upper boundary. Finite element model is shown in figure2.

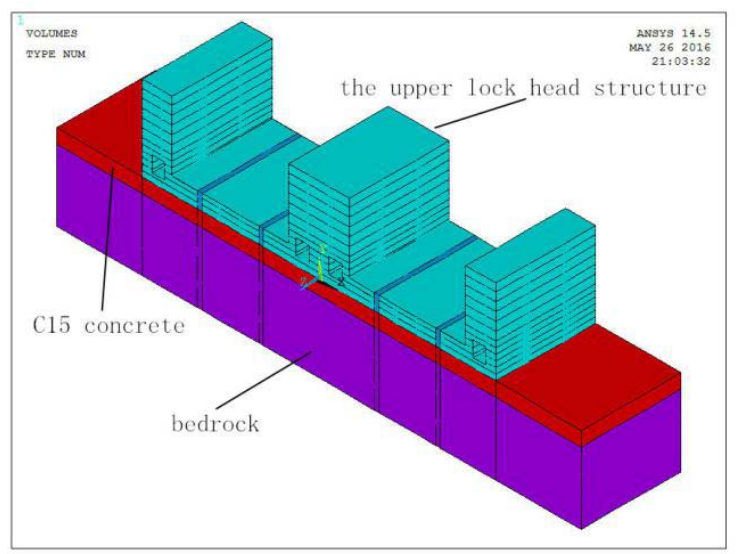

Fig. 2. Finite element model

The thermal unit adopts SOLID70 in ANSYS structural analysis which has a total of eight nodes and each node has only one temperature degree of freedom, it can be used for 3D steady-state and transient thermal analysis of the problem because there are three directions of heat conduction ability and it can achieve the uniform heat transfer. SOLID70 unit has a "element birth and death" function, it can respectively activates each layer concrete according to the construction pouring progress. And then we use the DO while loop language to control and apply the layers of the concrete hydration heat as well as the convective boundary conditions to achieve the the actual casting simulation. Using mapped meshing and selecting the unit side length $1 \mathrm{~m}$, the finite element discrete model is shown in figure 3.

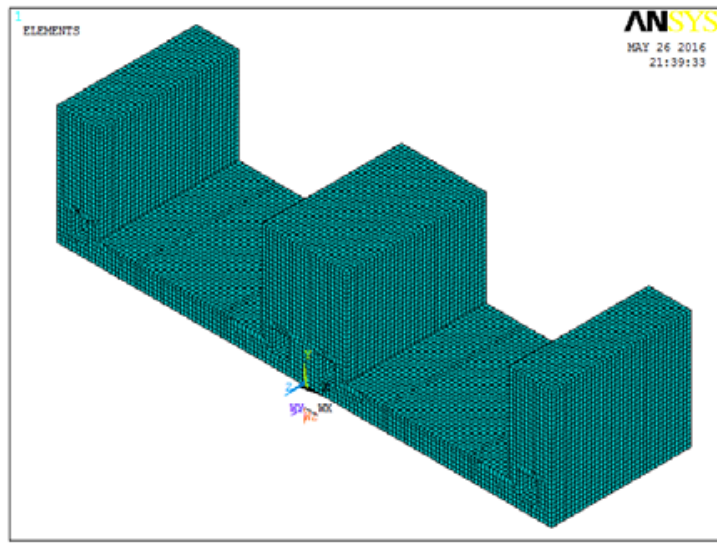

Fig. 3. Finite element model of upper lock head structure 


\section{Boundary Conditions}

It is adiabatic around and at the bottom of bedrock which belongs to the second category boundary condition [3]: the concrete surface heat flow $f$ is a known function of time $\tau$, as in

$$
-\lambda(\partial T / \partial n)=f(\tau)
$$

Where: $n$ is the normal direction of the concrete surface; $\lambda$ is the thermal conductivity of concrete. When $\partial T / \partial n=0$, for the adiabatic boundary conditions.

There exists thermal convection flow between air with bedrock surface, outer surface of the upper lock head structure and the conduit culvert which belongs to the third category boundary condition[3]: When the concrete in contact with air, the surface heat flow is proportional to the difference of the concrete surface temperature $T$ and the air temperature $T_{a}$, as in

$$
-\lambda(\partial T / \partial n)=\beta\left(T-T_{a}\right)
$$

Where: $\beta$ is an exothermic coefficient, $W /\left(m^{2} \cdot{ }^{\circ} \mathrm{C}\right)$.

The concrete of the floor of the lock contacts with the replacement concrete of bedrock, there exists temperature transfer which belongs to the fourth category boundary condition[3]: When two different solid contact, such as a good contact, then the contact surface temperature and heat flow are continuous, as in

$$
\left.\begin{array}{l}
T_{1}=T_{2} \\
\lambda_{1}\left(\partial T_{1} / \partial n\right)=\lambda_{2}\left(\partial T_{2} / \partial n\right)
\end{array}\right\}
$$

Where: $\lambda_{1}$ and $\lambda_{2}$ are respectively thermal conductivities of the bedrock and concrete.

The temperature changes of external environment will be applied as a surface load on the concrete surface. In the calculation process of the analysis, the simulation of the upper lock head structure mainly uses the "element life and death" function and APDL command to realize the change of the initial and boundary conditions. Firstly, kill all the lock unit group by using EKILL command, and then activate the layer of concrete unit group through EALIVE command, this indicates that pouring a layer is completed. At the same time achieve the pouring process of the simulation through conditions control and DO loop order.

\section{Parameter Selection}

\section{1) Environment temperature}

The statistical meteorological elements of Changsha integrated hub are mainly based on observations from 1951 to 2001 in Changsha weather stations near the dam site. The annual and monthly average temperature of Changsha weather stations can be summarized as shown as table 2 .

The environment temperature changes in ANSYS can be simulated by sinusoidal expression[4], because the temperature varies with the change of the seasons

$$
T(\tau)=T_{a}+T_{b} \sin \omega\left(\tau-\tau_{a}\right)
$$

TABLE II. THE ANNUAL AND MONTHLy AVERAge TEMPERATURE OF CHANGSHA WEATHER STATIONS $\left({ }^{\circ} \mathrm{C}\right)$

\begin{tabular}{|c|c|c|c|c|c|}
\hline Time & January & February & March & April & $\begin{array}{c}\text { annual } \\
\text { average }\end{array}$ \\
\hline Temp & 5.3 & 6.7 & 11.1 & 17.2 & \\
\cline { 1 - 4 } Time & May & June & July & August & \multirow{2}{*}{17.4} \\
\cline { 1 - 4 } Temp & 22.3 & 25.9 & 29.3 & 28.8 & \\
\cline { 1 - 4 } Time & September & October & November & December & \\
\cline { 1 - 4 } Temp & 24.3 & 18.6 & 12.9 & 7.5 & \\
\hline
\end{tabular}

Where: $T$ is the temperature $\left({ }^{\circ} \mathrm{C}\right) ; T_{a}$ is the annual average temperature $\left({ }^{\circ} \mathrm{C}\right) ; T_{b}$ is air temperature monthly variation amplitude $\left({ }^{\circ} \mathrm{C}\right)$; $\tau$ is time $(\mathrm{d}) ; \tau_{a}$ is time of the highest temperature $(\mathrm{d})$.

\section{2) Simplified Foundation Temperature Field}

According to some engineering examples, in the depth of $5.0 \mathrm{~m}$ below the foundation temperature is close to the annual average temperature, and $10.0 \mathrm{~m}$ below is basically the annual average temperature.

Therefore, using the following ways to consider the foundation temperature field in the temperature field calculation: Ground surface temperature field is taken as the starting time of the environment temperature, depth below $10.0 \mathrm{~m}$ taken as the foundation of the annual average temperature. Table 1 shows that the temperature is close to the annual average temperature when starting pouring in April, thereby foundation temperature field select $17.2{ }^{\circ} \mathrm{C}$.

\section{3) Thermodynamic Parameters of Concrete}

Adopt the compound exponential by Zhu Bofang academician[5], which was expressed as:

$$
Q(t)=Q_{0}\left(1-e^{-a t^{b}}\right)
$$

Where: $Q(t)$ is concrete hydration heat; $Q_{0}$ is the final heat of hydration; $a$ and $b$ are coefficients.

$Q_{0}$ and $a, b$ should be determined based on on-site construction of concrete mix experimentally or can also get reverse thrust based on field data. Rough calculation according to table 3 values

TABLE III. HYdRATION HEAT CONSTANTS OF CEMENT

\begin{tabular}{|c|c|c|c|c|}
\hline \multicolumn{2}{|c|}{ Cement types } & $Q_{0} /\left(J \cdot g^{-1}\right)$ & a & b \\
\hline \multirow{2}{*}{$\begin{array}{c}\text { ordinary Portland } \\
\text { cement }\end{array}$} & no. 425 & 330 & 0.69 & 0.56 \\
\cline { 2 - 5 } & no.525 & 350 & 0.36 & 0.74 \\
\hline $\begin{array}{c}\text { ordinary Portland cement for } \\
\text { dam no.525 }\end{array}$ & 270 & 0.79 & 0.70 \\
\hline $\begin{array}{c}\text { ordinary Portland slag cement for } \\
\text { dam no.425 }\end{array}$ & 285 & 0.29 & 0.76 \\
\hline
\end{tabular}

In ANSYS, the calculated value of hydration heat can not simply be applied as boundary conditions but to be applied by heat generation rate HGEN [6], which is expressed as: 


$$
H G E N=W_{C} d Q(t) / d t
$$

Where: HGEN is heat of hydration heat production rate of concrete, $W / m^{3} ; W_{C}$ is cement dosage per unit volume concrete, $\mathrm{kg} / \mathrm{m}^{3}$.

The APDL language is as follows:

HE00 $=83721 * 0.69 * \mathrm{DAY}^{* *}(-0.44) * \exp \left((-0.69) * \mathrm{DAY}^{* *} 0.56\right)$

\section{BFE,ALL,HGEN,,HE00}

\section{4) Other parameters}

The lock starts pouring in April with a duration of 13 months. The pouring of concrete warehousing temperature control in $17{ }^{\circ} \mathrm{C}$ and set up the insulation layer after pouring is completed. The deck of the concrete uses double conservation of geotextile and plastic sheeting, lateral and upstream and downstream face use foam board insulation. The heat transfer coefficient of the insulation layer can be calculated as follows:

$$
\beta=1 /\left\lfloor\Sigma \delta_{i} / \lambda_{i}+1 / \beta_{q}\right\rfloor
$$

Where: $\beta$ is the heat transfer coefficient of concrete surface insulation layer, $W /\left(\mathrm{m}^{2} \cdot k\right) ; \delta_{i}$ is the thickness of the insulation material, $m ; \lambda_{i}$ is the thermal conductivity of various insulation materials, $W /(m \cdot k) ; \beta_{q}$ is solid heat transfer coefficient in the air, taking $23, W /\left(m^{2} \cdot k\right)$.

In the actual maintenance, we use a layer of geotextile and a layer of plastic film with aggregate thickness of $5 \mathrm{~mm}$. we can calculate that $\beta=320 \mathrm{KJ} /\left(\mathrm{m}^{2} \cdot \mathrm{K}\right)$ by the type. And the thickness of foam board is $1.5 \mathrm{~cm}$, it can calculated that $\beta=183 K J /\left(m^{2} \cdot K\right)$.

The material parameters of the rock and soil body and concrete are shown in table 4:

TABLE IV. CALCUlation MOdEl PARAmeter TABLE

\begin{tabular}{|c|c|c|}
\hline Characteristics & Concrete & Pedestal Rock \\
\hline Density/ $\left(\mathrm{kg} \cdot \mathrm{m}^{-3}\right)$ & 2400 & 1900 \\
\hline Specific heat $\left(\mathrm{J} \cdot /\left(\mathrm{g} \cdot{ }^{\circ} \mathrm{C}\right)\right)$ & 0.97 & 0.88 \\
\hline Thermal conductivity/ $\left(\mathrm{kJ} \cdot /\left(\mathrm{m} \cdot \mathrm{d} \cdot{ }^{\circ} \mathrm{C}\right)\right)$ & 254.4 & 289.3 \\
\hline Poisson's ratio & 0.18 & 0.20 \\
\hline Elasticity modulus/ $\mathrm{GPa}$ & 2.8 & 1.0 \\
\hline
\end{tabular}

\section{Calculation Results and Analysis}

Based on the above analysis of each section, and according to the construction schedule of APDL file through the transient analysis by ANSYS, the ideal results are obtained. In order to get an intuitive observation about the temperature change inside the concrete, the upper lock head is sliced to get the temperature field cloud picture and temperature time curve of each time and each part. Figure 1 shows the temperature variation curve of pouring the first layer of bottom slabs. Figure 1 illustrates the concrete hydration heat temperature rising to the highest temperature around 3 days and it meets the exothermic regularity of concrete hydration heat [7]. Therefore, we mainly have a view of the third day temperature change after the concrete pouring.

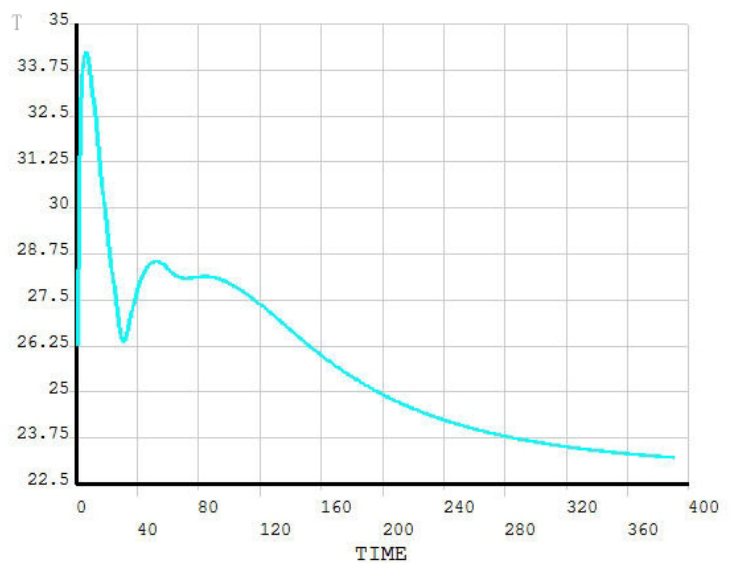

Fig. 4. Thermogenic curves of cement hydration of the first layer.

Figure 5 is the bottom slabs temperature field cloud picture of the 33th day, 63th day, 93th day and 123th day. The figure 2 shows that the highest temperature of concrete on the 33th day is $38.1^{\circ} \mathrm{C}, 32.3^{\circ} \mathrm{C}$ on the 63th day , $26.2^{\circ} \mathrm{C}$ on the 93th day, and $20.5^{\circ} \mathrm{C}$ on the 123th day. In the case of three layers pouring, the total temperature falls after the completion of the bottom slabs pouring is 11.8 , and the average temperature rise is $0.2^{\circ} \mathrm{C} / \mathrm{d}$. This is mainly because the bottom slabs reserve wide seam which reduces the volume of pouring that resulted in less hydration heat rise and reducing the likelihood of temperature cracks.

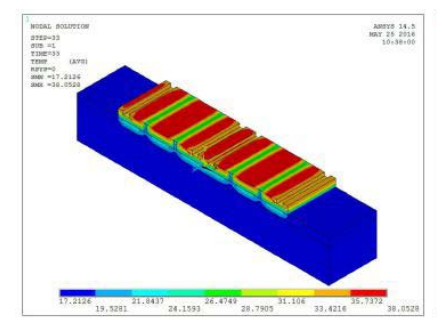

a)33d

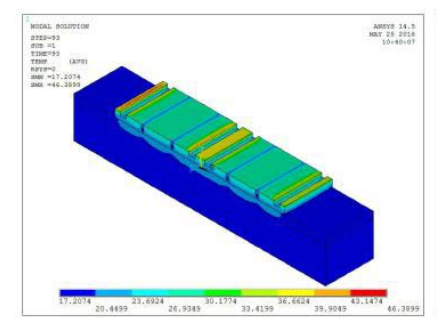

c)33d

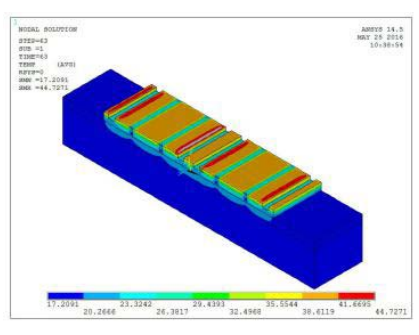

b)63d

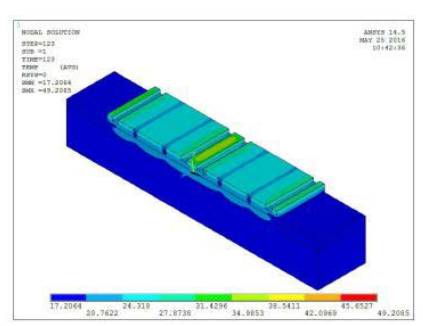

d) $63 d$
Fig. 5. Temperature field of the 33d, 63d, 93d and 123d of the baseplate.

Figure 6 is the temperature time curve of the central of the upper lock structure nearby the water transmission way. Figure 3 shows the temperature decreases slowly, after 27 days break from the 93 days to 120 days the temperature only 
dropped $7.4{ }^{\circ} \mathrm{C}$. The temperature can not be effectively reduced and the temperature difference between inside and outside of here is $10.2^{\circ} \mathrm{C}$. Thus, the concrete nearby the water transmission way may occur cracks due to thermal expansion. The reason causing this result was mainly due to the large volume of concrete here and the smaller convection contact area.

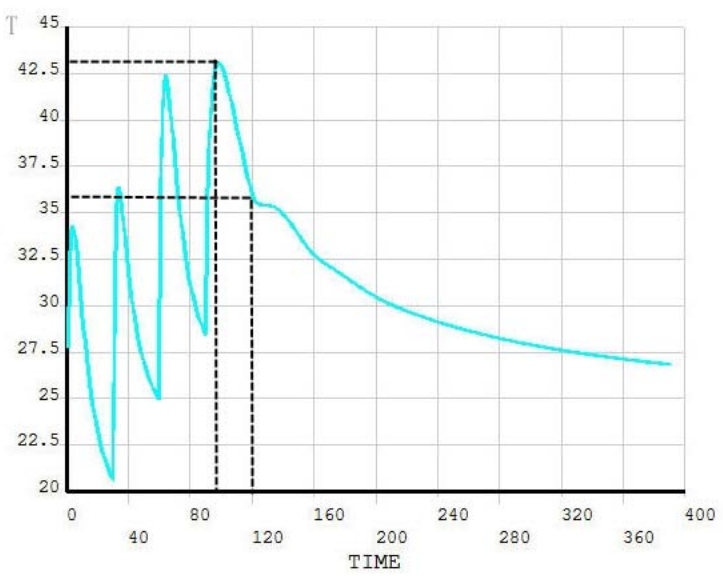

Fig. 6. The temperature time curve of the central of the upper lock structure nearby the water transmission way.

Figure 4 is the temperature field cloud picture of the reserved wide seam. The figure 4 illustrates that the maximum hydration heat temperature rise is 14.5 which meets the specification requirements. And temperature of the bottom slabs when pouring the reserved wide seam has dropped to approximately that of the ambient temperature, so it will not affect the overall stability of the bottom slabs.

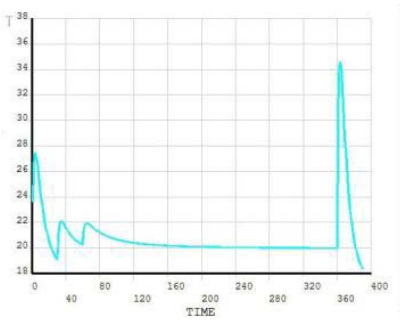

a)temperature-time curve

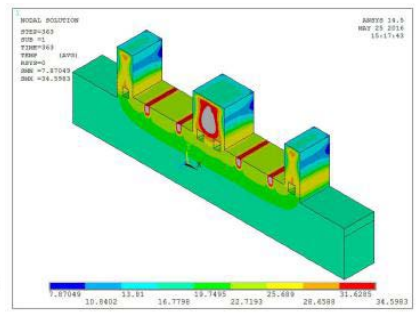

b)temperature field cloud picture
Fig. 7. Temperature field of the reserving wide seam.

\section{CONCLUSION}

When using ANSYS analysis of concrete, it should pay attention to establish a reasonable finite element model based on topographic and geologic conditions, environmental characteristics and construction time. And in the calculation we should take into account all elements of the convection between the structure, bedrock and the air, as well as the heat transfer of concrete structure and the bedrock. For the analysis of complex structures, we also need to use the powerful ANSYS APDL language to implement this process.

Through the analysis of the temperature field cloud picture and temperature time curve, we can see: The maximum temperature and average temperature rise are not high after the bottom slabs usingthe construction method of reserving wide seam and it reduces the possibility of temperature cracks.

But due to the concrete volume at the bottom of the middle of the culvert is large, and the convection area is small, the temperature dropper slowly, the temperature difference between internal and external is high, there may be cracks caused by thermal expansion. Calculated results well reflect the rationality of the design results of the material selection, construction method and temperature control measures. It also has the functionof the feedback design, and has reference value on the installation of safety monitoring instruments in navigation lock.

\section{REFERENCES}

[1] Chen Yingbo, Li Xiucai, Zhang Xiong. Mass Concrete Simulation and Analysis for Temperature Field During Pouring[J]. Journal of Huazhong University of Science and Technology, 2004 (2) : 37-39.

[2] JTJ307-2001, Code for Design of Hydraulic Structures of Shiplocks[S].

[3] Zhu Bofang. Thermal Stresses and Temperature Control of Mass Concrete[M]. Beijing: China Electric Power Press, 1999.

[4] DL5077-1977, Specification for load design of hydraulic structures[S].

[5] Zhu Bofang. A method for computing the adiabatic temperature riseof concrete considering the effect of thetemperature of concrete[J]. Journal of Hydroelectric Engineering, 2003(02) : 69-73.

[6] Li Tiantian, Tang Xingrong. Finite Element Analysis of Hydration Heat Effect. Journal of Huaihai Institute of Technology, 2014(3): 54-59.

[7] J. C. Wang,P. Y. Yan. Influenceof initial casting temperature and dosage of fly ash on hydration heat evolutionof concrete under adiabatic condition[J]. Journal of Thermal Analysis and Calorimetry, 2006 (3): 755-760. 